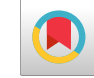

\title{
Association of Demographic, Social, and Personality Factors with Early Versus Late Divorce in Women: A Cross Sectional Study in Ilam, West of Iran
}

\author{
Sodabeh Alinejhad ${ }^{1}$, Yousef Veisani ${ }^{2}$, Sehat Aibod ${ }^{2}$, Akbar Azizifar $^{3}$, Mostafa Alirahmi $^{2}$ and Fathola \\ Mohamadian $^{4, *}$ \\ ${ }^{1}$ Department of Psychology, Faculty of Human Sciences, Islamic Azad University, Ilam Branch, Ilam, Iran \\ ${ }^{2}$ Psychosocial Injuries Research Center, Ilam University of Medical Sciences, Ilam, Iran \\ ${ }^{3}$ Department of Language Teaching, School of Medicine, Ilam University of Medical Sciences, Ilam, Iran \\ ${ }^{4}$ Department of Psychology, Psychosocial Injuries Research Center, Ilam University of Medical Sciences, Ilam, Iran \\ "Corresponding author: Department of Psychology, Ilam University of Medical Sciences, Psychosocial Injuries Research Center, Ilam University of Medical Sciences, Banganjab, \\ Ilam, Iran. Tel: +98-8432223510, Email: mobinmohamadian@yahoo.com
}

Received 2018 October 24; Revised 2019 June 14; Accepted 2019 June 22.

\begin{abstract}
Background: Divorce is an obscure phenomenon in marital life which has led many researchers to investigate its related factors. Objectives: The purpose of this study was to investigate demographic, social, and personality factors in women with early divorce versus those with late divorce.

Methods: The method of the present study is cross sectional, the statistical population of the study consisted of 389 divorced women who referred to the family court in the city of Ilam in 2016 and 2017. Among these, 196 were selected by simple random sampling method as the sample of the study; data were collected using demographic information questionnaire and NEO five-factor inventory (NEO-FFI). Finally, the data were analyzed using descriptive statistics and logistic regression analysis using SPSS software.

Results: Based on the results of this study, women's outside home employment $(\mathrm{P}<0.005)$ and religious beliefs at the beginning of marriage reduced early life divorce $(\mathrm{P}=0.038)$. The results also showed that considering the personality factors there was not a significant difference between the two groups $(\mathrm{P}=0.234)$.

Conclusions: Results showed that early marriage, lack of children, and living with the husband's father family are predictors of early- life divorce, also residence dissatisfaction, neuroticism, conscientiousness traits, and the desire for new experiences can be other predictors for early life divorce in women.
\end{abstract}

Keywords: Social Factors, Personality Factors, Divorce, Women

\section{Background}

Marriage is a complex, elegant, and dynamic relationship which can bring about physical well-being, comfort, and safety for the spouses and also family members (1). If they can not continue to live together safely and get divorced, there would be challenges which will affect the physical well-being and the feeling of security which will affect their future (2). Divorce is the most common cause of severe conflict and more than half of the couples seeking counseling finally get divorced (3). There are several factors that affect the occurrence of divorce including; economic, social, legal, psychological, and internal and external stressors among which individual and psychological factors are of particular importance (4). These factors, both individually and socially, interact with each other in- dependent of the relationship of the couple and may lead to a tendency toward divorce (2), since these factors are related to all aspects of people's lives, such as education, work, and interpersonal functions (5). Among these factors are personality factors, individual, and social factors (5). Personality is an attribute and distinctive pattern of excitement and behavior that affects the way an individual interacts with his or her physical and social environment. The five-factor model of personality is one of the major theories about the analysis of personality factors (6). These five factors are: neuroticism, extraversion, being open to new experience, acceptance, and conscientiousness. Research has shown that personality has sustained effects on marital relationships. Karney and Bradbury (7), argue that some personality tendencies, such as emotional instability 
or neuroticism create sustainability vulnerabilities that affect how couples adapt to stressful experiences. This adaptation also influences their satisfaction with marital relationships. Bouchard et al. (8), also believe that, neuroticism affects the perception of the spouses and some negative emotions can be caused by this feature. In a 13-year study, Caughlin et al. (9) concluded that a large part of the relationship between neuroticism and marital satisfaction was related to negative communication patterns among spouses which means, nefarious people express more negative emotions to spouses and thereby help to form negative interaction patterns in marital relationships. Kurdek (10) believes that high levels of conscientiousness makes them more conscientious and refrains them from showing violent behavior in marital relationships and inhibiting their impulses. Hart et al. (11), in a research concluded that men who have less conscientiousness respond to marital tensions by converting to alcohol and physical aggression. Similarly, Watson et al. (12) reported in their research that agreeableness, conscientiousness, and extroversion have a positive correlation with marital satisfaction. Researchers believe that experience makes couples more flexible and more active in solving their problems and conflicts. According to Tobin et al. (13), extraversion is a feature that is more closely related to an individual's social interactions and does not affect other characteristics of the quality of marital relationships and other intimate relationships. However, some studies demonstrate the effect of this feature on marital relationships. For example, in the Buss study (14), which relates to the personality characteristics that affect marital relationships, extroversion was related to the ways in which couples interact. Many studies have sought to answer the question of which factors affect divorce? Various factors have been mentioned regarding the socio-cultural context for the occurrence of the phenomenon of divorce. For example, Amato and Rogers (15), mentioned the betrayal of the wives as one of the divorce factors. Gaffal (16), indicated that individual factors (age, education, and socioeconomic status), communication (previous mental and emotional functions, or attachment to the ex-spouse) and mental health (self-esteem, individual coping skills, attitudes, and individual beliefs) are among the factors which lead to divorce. However, Mohsenzadeh et al. (17) considering the social culture of Iran indicated, premarital factors such as inappropriately motivated marriage and obligatory marriages and postmarital factors including conflicts with the spouse's family, low attendance of the husband at home, conflicts over gender-based attitudes, marital violence, betrayal, suspicion, and financial problems as the influential factors of divorce. From the perspective of women and men who experience divorce, different factors can be mentioned, as
Barikani et al. (18) showed, the most important reasons for men to separate and divorce is the family interference and for women it is the wrong selection of the husband. An examination of the empirical background points out that the factors affecting divorce are quite different from society to society and this confirms the need to consider the cultural context of society in order to prevent and reduce divorce as a social problem.

\section{Objectives}

The purpose of this study was to investigate demographic, social, and personality factors in women with early divorce versus late-divorced in the city of Ilam.

\section{Methods}

The method of the present study is cross sectional, the statistical population of the study included all divorced women in the city of Ilam. The subjects were entered into the study by simple random sampling. To determine the sample size, the Morgan table was used. In the years of 2016 and 2017 among 389 divorced women as the population, 196 were selected as the sample and then they were divided into two groups of early divorce (divorce before the age of 4 years from the date of formal contract) and late divorce (divorce after 4 years from the date of the formal contract). After we have completed and acquired the informed consent from women who were referring to the family court, they filled the questionnaires there. In addition to the demographic information questionnaire, NEO five-factor inventory was used to collect data. In the demographic information questionnaire, two parts of the personal information (age, sex, education, type of marriage, place of birth, income) and social information of the divorce were included (failure to meet the expectations of the spouses of one another, the interference of others, the positive image of the consequences of the divorce, addiction, the absence of a baby, marital status, the amount of dowry, couples' interest in one another, female employment outside the home, misunderstanding of beliefs) were addressed. The short form of the NEO questionnaire was used to measure the five major factors of personality. This questionnaire is actually a shortened Inventory of 240 questions from NEO-personality inventory-revised (NEO-PIR), The inventory also has a short form called (NEO-FFI), which is a 60-question questionnaire. This form has been used in this study with 60 questions that McCrae (19) used to assess five personality factors such as neuroticism, extroversion, empiricism, conscientiousness, and agreeableness based on a five-point Likert scale from completely disagree $=1$, disagree $=2$, no idea $=3$, agree $=4$, to completely agree $=5$ 
and in some phrases, the inventory is scored in reverse, that is: completely disagree $=5$, disagree $=4$, no idea $=3$, agree $=2$, to completely agree $=1$ scored. The questionnaire was completed by the sample of the study who were 196 divorced women referring to the family court in the city of Ilam. The coefficient of test-retest reliability of this inventory has been reported between 0.75 and 0.83 in the Haghshenas study, also in this study the internal consistency coefficients for each of the factors of neuroticism, extroversion, experiences, conscientiousness and agreeableness was reported, $0.81,0.71,0.57,0.83$ and 0.71 respectively (20). McCrae and Costa (21), in a study to revise the NEO-FFI Inventory on 1492 adults reported Cronbach's alpha coefficients and the five factors of neuroticism, extroversion, experiencing, agreeableness, and conscientiousness as 0.86 , $0.80,0.75,0.69$ and 0.79 respectively.

\subsection{Stastical Analysis}

The data were analyzed using descriptive statistics including, mean, frequency of variables chi-squared test and logistic regression analysis including odds ratio (OR) and confidence interval 95\% (CI 95\%), the outcome variable was recoded into binary $(0,1)$ variable as early-life divorce, by significance level lower than 5\%, using SPSS 22 software.

\section{Results}

In this study, a total of 196 individuals were enrolled in two groups with early and late marriage. According to the results, the ratio of early divorce was different in all age groups $(\mathrm{P}=0.005)$. Also, there was no significant difference in the distribution of educational level among the two groups $(\mathrm{P}=0.749)$. But the frequency rate of early divorce was higher in people with B.A and M.A education. The frequency rate of early divorce of unemployed people was two times more than of employed people $(\mathrm{P}=0.116)$. In the case of people who had lived in a paternal family after marriage, the early divorce was 10\% higher. In early and late divorces, $76.5 \%$ and $83.7 \%$ of cases were the women who were seeking divorce, respectively. The percentage and frequency of other demographic variables are shown in Table 1.

In this study, the association between social factors and early divorce was investigated using logistic regression model. In this model, the impact of factors including unrealized expectations, misunderstandings, interference of others in marital affairs, positive perceptions of the consequences of divorce, female out-of-home employment, female addiction, husband's addiction, dissatisfaction with housing, lack of interest in the spouse, and the absence of a child was investigated on early divorce. Based on the results shown in Table 2, female out-of-home employment
Table 1. Distribution of Demographic Variables in Two Groups of Women with Early and Late Divorce ${ }^{\mathrm{a}}$

\begin{tabular}{|c|c|c|c|}
\hline Demographic Variables & Early & Late & P Value \\
\hline Groups & $98(50)$ & $98(50)$ & \\
\hline Age categories, y & & & 0.005 \\
\hline $16-25$ & $11(11.2)$ & 11.0() & \\
\hline $26-35$ & $60(61.2)$ & $51(52.0)$ & \\
\hline $36-45$ & $24(24.5)$ & $42(42.9)$ & \\
\hline $46-55$ & $3(3.1)$ & $3(3.1)$ & \\
\hline $56-65$ & $0(0)$ & $1(1.0)$ & \\
\hline Education & & & 0.749 \\
\hline Illiterate and elementary & $3(3.1)$ & $6(6.1)$ & \\
\hline $\begin{array}{l}\text { Secondary school and high } \\
\text { school }\end{array}$ & $35(35.7)$ & $38(38.8)$ & \\
\hline Over diploma & $25(25.5)$ & $26(26.5)$ & \\
\hline B.A & $29(29.6)$ & $23(23.5)$ & \\
\hline M.A & $6(6.1)$ & $5(5.1)$ & \\
\hline Job & & & 0.116 \\
\hline Employee & $5(5.1)$ & $10(10.2)$ & \\
\hline Free & $18(18.4)$ & $19(19.4)$ & \\
\hline Housewife & $50(51.0)$ & $53(54.1)$ & \\
\hline Unemployed & $21(21.4)$ & $9(9.2)$ & \\
\hline Others & $4(4.1)$ & $7(7.1)$ & \\
\hline living place after marriage & & & 0.120 \\
\hline Personal & $29(29.6)$ & $24(24.5)$ & \\
\hline Fatherhood & 50() 51.0 & $40(40.8)$ & \\
\hline Relatives & $1(1.0)$ & $2(2.0)$ & \\
\hline Rental & $18(18.4)$ & $32(32.7)$ & \\
\hline Number of children & & & 0.000 \\
\hline Zero & $78(79.6)$ & $29(29.6)$ & \\
\hline 1 & $19(19.4)$ & $46(46.9)$ & \\
\hline 2 & $1(1.0)$ & $21(2.4)$ & \\
\hline 3 and more & $0(0.0)$ & $2(2.0)$ & \\
\hline Type of marriage & & & 0.500 \\
\hline Obligatory & $71(72.4)$ & $70(71.4)$ & \\
\hline With personal consent & $27(27.6)$ & $28(28.6)$ & \\
\hline Place of birth & & & 0.234 \\
\hline City & $80(81.6)$ & $86(87.8)$ & \\
\hline Village & $18(18.4)$ & $12(12.2)$ & \\
\hline Type of divorce & & & 0.235 \\
\hline An agreement & $18(18.4)$ & $16(16.3)$ & \\
\hline Legal & $76(77.6)$ & $77(78.6)$ & \\
\hline Absent & $4(4.1)$ & $5(5.1)$ & \\
\hline Divorce applicant & & & 0.141 \\
\hline Man & $23(23.5)$ & $16(16.3)$ & \\
\hline Woman & $75(76.5)$ & $82(83.7)$ & \\
\hline
\end{tabular}

$\mathrm{OR}=0.35$ ( $\mathrm{Cl}$ \%95: $0.17-0.73)$ and also religious beliefs $\mathrm{OR}$ $=0.69(\mathrm{CI} \% 95: 0.53-0.96)$ at the beginning of marriage reduced the rate of early divorce. In turn, the interference of others $\mathrm{OR}=1.47(\mathrm{CI} \% 95: 1.09-1.73)$ and the unrealized expec- 
tations $\mathrm{OR}=1.24$ (CI \%95: 1.12 - 1.47) of wife causes an earlier divorce. In addition, female out-of-home employment OR $=1.13(\mathrm{CI} \% 95: 0.57-2.22)$ and also religious beliefs $\mathrm{OR}=1.38$ (CI \%95: 0.71 - 2.66) during married life does not lead to a reduction in late divorce. In turn, the interference of others $\mathrm{OR}=0.71$ (CI\%95: 0.36 - 1.41) showed no significant effect on late divorce. Moreover, the unrealized expectations OR $=1.25$ (CI \%95: $0.65-2.40)$ of wife were related to a late divorce.

Table 3 shows the mean and standard deviation of personality characteristic scores in women with early divorce against late-divorce. Based on the results, the difference in mean of personality characteristics in the two groups was not significant $(\mathrm{P}>0.05)$. Based on the results, the mean score of neuroticism among women with early divorce (37.57) was higher than that of late-divorced (36.52), although this difference was not significant $(\mathrm{P}=0.362)$. Also, the mean score of the openness to experience among women with early divorce (38.58) was higher than that of late-divorced (37.73) which was not statistically significant $(P=0.234)$.

\section{Discussion}

The purpose of this study was to compare individual, social, and personality characteristics with early divorce among divorced women. In this study, from the point of view of divorced women, the effect of factors of unrealized expectations, misunderstandings, interference of others in marital affairs, positive perceptions of the consequences of divorce, female out-of-home employment, female addiction, spouse's addiction, dissatisfaction with housing, the lack of interest in the spouse, and the absence of a child on early divorce was investigated. According to the results of the survey, female out-of-home employment and having religious beliefs at the beginning of marriage has reduced early divorce rates. The findings of this study are consistent with the results of Kalmijn and van Groenou (22), Paris and Luckey (23), about the collapse of families due to the fall of religious and moral values, and are inconsistent with John et al. (24). Kalmijn in his research has concluded that religious beliefs of individuals regulate their behavior and lessen divorce (22). A study by John et al. entitled "Women's Employment and the Instability of Married Life Based on an Example of Thailand", shows that women's employment is effective in marital life which increases the instability of marital life (24). In contrast, the interference of others and the unrealized expectations of the wife increased early divorce. This finding is consistent with the findings of Fatehi Zadeh et al. (25), Zargar and NeshatDoost (26), Moshki et al. (27), Jalili et al. (28), and Whisman et al. (29). Fatehi Zadeh et al. concluded that family factors such as religious beliefs, family involvement, lack of family support for divorce, and parental economic support were effective in low divorce rates (25). Family interference in couples' life has been one of the factors affecting divorce. Zargar and Neshat-Doost's research also showed that the most important causes of divorce in Falavarjan city during 2003-2005 were communication problems, addiction, family interference, and mental illness of one of the couples (26).

According to Moshki et al. and Nazari's research, the type of interaction between family and couples can play an important role in the sustainability of couples' marital life, or in contrast, in the collapse and dissolution of it $(27,28)$.

To explain the findings of this study; the highlighted role of the families in the event of divorce is undeniable. Today, there is a huge gap between tradition and modernity in the family. Many parents try to manage the lives of their children based on traditional and ancient principles, while today's generation has come up with new beliefs and values as they want to become more independent and create a core family. In our society, the family is shaped traditionally, but our divorces are exactly influenced by modern values. From the viewpoint of the participants in this study, unrealized expectations on the part of the wife and family interference are among the factors which lead to early divorce. Interference is the strongest predictor (28). Indirect interference among family members in Iran is one of the problems that increase marital problems and family disputes between couples. Since couples do not show aggression against people around them, this aggression will be shown between the couples, which causes marital disputes between them. Neglect is also one of the problems that can disrupt couples. Because of the lack of attention, especially emotional attention of men to women, women feel that their men do not love them and they do not pay attention to their desires which may play a role in marital disturbances (29).

The results also showed that according to the fivefactor theory of personality, there is no significant difference between women with early divorce and late divorce in the sub-scales of introversion-extraversion, neuroticism, conscientiousness, experiences, and agreeableness. The findings of the study are in line with Weiser and Weigel (30); Dorros et al. (5); Furnham (6); Rogge et al. (31); Shackelford et al. (32); Donnellan et al. (33); Diener et al. (34); Behrouz et al. (35). To explain the findings; personality characteristics are important personal factors that play an important role as an interpersonal factor in how each partner copes with stress and life problems, and can determine whether a relationship is healthy or unhealthy and the couples tend to divorce or go to a kind of problem-solving relationship $(4,5)$. Rogge et al. (31) concluded that neuroti- 


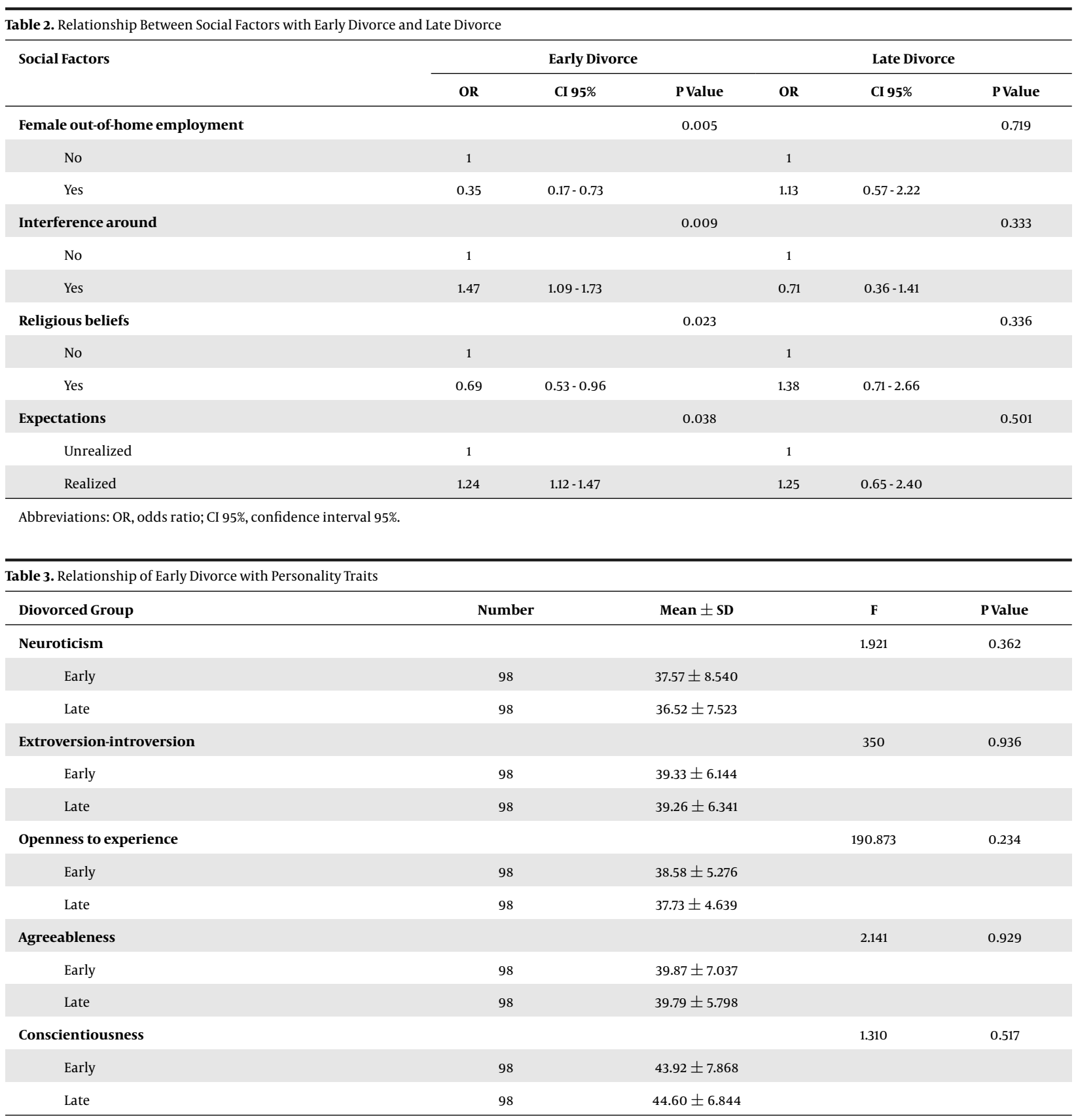

cism and aggression had an effect on the rate of early decline in marital life. Neuroticism seems to affect the relationship and interactions of individuals with each other. In other words, high risk of neuroticism may indirectly lead to divorce by increasing dissatisfaction with marital life. According to McCarry and Moshki (21) Eagerness to new experience causes couples to use more creativity in solving their problems and conflicts and to use more flexible and active coping strategies in solving their problems.
Research has shown that new experiences lead to greater sexual satisfaction in couples and lead to increased attention to the opposite side (5). Agreeableness is also a personality characteristic that is associated with empathy, cooperation, trust, and support in interpersonal relationships which due to creating consensus alongside paying attention to the expectations and similarities at the time of conflict among couples would lead to marital adjustment and consequently, it reduces the probability of divorce (35). 
The best concept for conscientiousness is "will”. Conscientious people have a great will, get more academic and professional achievements, and subsequently experience less tensions. These people are less exposed to stress, pressure, and marital conflicts, and because of their commitment to ethics, they tend to be less likely to have divorce. Another feature of personality is introversion-extraversion; two extraversion qualities of positive thinking and high energy may lead to less conflict (34). Consequently, extraversion as a positive factor that may play a role in marital and family functions and prevent marital dissatisfaction and ultimately divorce.

\subsection{Conclusions}

As discussed in the article, divorce is an obscure phenomenon in marital life which has led many researchers to investigate the influential factors. The study concluded that women's outside home employment and religious beliefs at the beginning of marriage reduced early life divorce. The study also concluded that considering the personality factors, there was not a significant difference between the two groups of early-life divorce and late-life divorce.

The results of the study showed that early marriage, lack of children, and living with the husband's father family are predictors of early-life divorce, also residence dissatisfaction, neuroticism, conscientiousness traits, and the desire for new experiences can be other predictors for early-life divorce in women. As it is common with different studies, this study had some limitations including; the divorced women were not interested in participating in the study and filling out the questionnaire, also the abundant number of the questions was tiresome to the responders, and finally since the responders were from the city of Ilam it makes the results of the study not to be generalizable enough.

\section{Acknowledgments}

We would like to thank all the participants involved in the study. Special thanks to the management, research assistant and Psychology Department at Ilam Islamic Azad University, Ilam Branch, women participating in the research, and all those who helped us with this research.

\section{Footnotes}

Authors' Contribution: Study concept and design: Sodabeh Alinejhad and Fathola Mohamadian. Analysis and interpretation of data: Yousef Veisani and Sehat Aibod.
Drafting of the manuscript: Akbar Azizifar and Mostafa Alirahmi. Critical revision of the manuscript for important intellectual content: Sodabeh Alinejhad, Yousef Veisani, Sehat Aibod, Akbar Azizifar, Mostafa Alirahmi and Fathola Mohamadian. Statistical analysis: Yousef Veisani and Sehat Aibod.

Conflict of Interests: The authors not declare any conflict of interest.

Financial Disclosure: This study was not financially supported by any organization.

Ethical Approval: This article is the result of a Master's thesis of Clinical Psychology from Islamic Azad University, Ilam Branch (the ethics code of IR.MEDILAM.REC.1394.117).

Patient Consent: The informed consent was acquired from participants before completing the questionnaire.

\section{References}

1. Panahifar S, Yousefi N, Amani A. The effectiveness of schema-based couple therapy on early maladaptive schemata adjustment and the increase of divorce applicants adaptability. Kuwait Chapter Arab J Bus Manag Rev. 2014;3(9):339-46. doi:10.12816/0018357.

2. Amato PR. Research on divorce: Continuing trends and new developments. J Marriage Fam. 2010;72(3):650-66. doi: 10.1111/j.17413737.2010.00723.x.

3. Worthington EL. Hope-focused marriage: Recommendations for researchers, clinicians, and church workers. J Psychol Theol. 2018;31(3):231-9. doi: 10.1177/009164710303100308.

4. Provencher V, Begin C, Gagnon-Girouard MP, Tremblay A, Boivin S, Lemieux S. Personality traits in overweight and obese women: Associations with BMI and eating behaviors. Eat Behav. 2008;9(3):294-302. doi: 10.1016/j.eatbeh.2007.10.004. [PubMed: 18549988].

5. Dorros S, Hanzal A, Segrin C. The Big Five personality traits and perceptions of touch to intimate and nonintimate body regions.J Res Pers. 2008;42(4):1067-73. doi: 10.1016/j.jrp.2007.11.004.

6. Furnham A. Relationship among four Big Five measures of different length. Psychol Rep. 2008;102(1):312-6. doi: 10.2466/pro.102.1.312-316. [PubMed: 18481692].

7. Karney BR, Bradbury TN. Neuroticism, marital interaction, and the trajectory of marital satisfaction.J Pers Soc Psychol.1997;72(5):1075-92. doi: 10.1037/|0022-3514.72.5.1075. [PubMed: 9150586].

8. Bouchard G, Lussier Y, Sabourin S. Personality and marital adjustment: Utility of the five-factor model of personality. J Marriage Fam. 1999;61(3):651-60. doi: 10.2307/353567.

9. Caughlin JP, Huston TL, Houts RM. How does personality matter in marriage? An examination of trait anxiety, interpersonal negativity, and marital satisfaction. J Pers Soc Psychol. 2000;78(2):326-36. doi: 10.1037||0022-3514.78.2.326. [PubMed:10707338].

10. Kurdek LA. Predicting marital dissolution: A 5-year prospective longitudinal study of newlywed couples. J Pers Soc Psychol. 1993;64(2):22142. doi: 10.1037/0022-3514.64.2.221.

11. Hart SD, Dutton DG, Newlove T. The prevalence of personality disorder among wife assaulters. J Pers Disord. 1993;7(4):329-41. doi: 10.1521/pedi.1993.7.4.329.

12. Watson D, Hubbard B, Wiese D. General traits of personality and affectivity as predictors of satisfaction in intimate relationships: Evidence from self- and partner-ratings. J Pers. 2000;68(3):413-49. doi: 10.1111/1467-6494.00102. [PubMed: 10831308]. 
13. Tobin RM, Graziano WG, Vanman EJ, Tassinary LG. Personality, emotional experience, and efforts to control emotions. J Pers Soc Psychol. 2000;79(4):656-69. doi: 10.1037/0022-3514.79.4.656. [PubMed: 11045745].

14. Buss DM. Manipulation in close relationships: five personality factors in interactional context. J Pers. 1992;60(2):477-99. doi: 10.1111/j.1467 6494.1992.tb00981.x. [PubMed: 1635051].

15. Amato PR, Rogers SJ. A longitudinal study of marital problems and subsequent divorce. J Marriage Fam. 1997;59(3):612-24. doi: $10.2307 / 353949$.

16. Gaffal M. Factors influencing ex-spouses' adjustment to divorce. Psychosocial and legal perspectives of marital breakdown. Springer; 2010. $\mathrm{p}$. 47-81. doi: 10.1007/978-3-642-13896-6_2.

17. Mohsenzadeh F, Nazariy AM, Arefi M. [Qualitative study of factors contributing to marital dissatisfaction and applying for divorce (the case of Kermanshah)]. Strateg Stud Women. 2011;14(53):7-42. Persian.

18. Barikani A, Ebrahim SM, Navid M. The cause of divorce among men and women referred to marriage and legal office in Qazvin, Iran. Glob J Health Sci. 2012;4(5):184-91. doi: 10.5539/gjhs.v4n5p184. [PubMed: 22980391]. [PubMed Central: PMC4776964].

19. McCrae RR, Costa PT, Martin TA, Oryol VE, Rukavishnikov AA, Senin IG et al. Consensual validation of personality traits across cultures.J Res Pers. 2004;38(2):179-201. doi: 10.1016/s0092-6566(03)00056-4.

20. Haghshenas H. [Persian version and standardizljtion of NED personality inventory-revised]. Iran J Psychiatry Clin Psychol. 1999;4(4):38-48. Persian.

21. McCrae RR, Costa PT. A contemplated revision of the NEO five-factor inventory. Pers Individ Differ. 2004;36(3):587-96. doi: 10.1016/s01918869(03)00118-1.

22. Kalmijn M, van Groenou MB. Differential effects of divorce on social integration. J Soc Pers Relatsh. 2016;22(4):455-76. doi 10.1177/0265407505054516.

23. Paris BL, Luckey EB. Longitudinal study in marital satisfaction. Soc Soc Res. 1991;50(2):212-6.

24. John N, Edwards TDF, Sairudee Vorakitphokatorn and Santhat Sermsri. Female employment and marital instability: Evidence from Thailand. J Marriage Fam. 1992;54(1):59-68. doi: 10.2307/353275.
25. Fatehi Zadeh M, Behjati Ardakani F, Nasr Esfahani A. Effect of family factors the low divorce statistics in Cities of Yazd, Ardakan and Meybod. Educ Psychol Stud. 2006;6:117-36.

26. Zargar F, Neshat-Doost HT. [Divorce incidence factors in Falavarjan Township]. J fam res. 2007;3(3):737-49. Persian.

27. Moshki M, Shahghasemi Z, Delshad Noghabi A, Moslem A. [The survey of condition and related factors to divorce from divorced couples' viewpoint of Gonabad city in 1387-88]. Horizon Med Sci.2011;17(1):35-44. Persian.

28. Jalili L, Najar S, Nezamivand-Chegini S, Yaralizadeh M. The relationship between factors related to divorce request and mental health among divorce applicant women referred to legal medicine organization in Ahvaz, Iran. J Family Reprod Health. 2017;11(3):128-37. [PubMed: 30018649]. [PubMed Central: PMC6045693].

29. Whisman MA, Dixon AE, Johnson B. Therapists' perspectives of couple problems and treatment issues in couple therapy.J Fam Psychol. 1997;11(3):361-6. doi:10.1037/0893-3200.11.3.361.

30. Weiser DA, Weigel DJ. Investigating experiences of the infidelity partner: Who is the "other man/woman"? Pers Individ Differ. 2015;85:176-81. doi: 10.1016/j.paid.2015.05.014.

31. Rogge RD, Bradbury TN, Hahlweg K, Engl J, Thurmaier F. Predicting marital distress and dissolution: Refining the two-factor hypothesis. J Fam Psychol. 2006;20(1):156-9. doi: 10.1037/0893-3200.20.1.156. [PubMed: 16569100].

32. Shackelford TK, Besser A, Goetz AT. Personality, marital satisfaction, and probability of marital infidelity. Individ Differ Res. 2008;6(1):13-25.

33. Donnellan MB, Conger RD, Bryant CM. Erratum to "The big five and enduring marriages" [Journal of Research in Personality 38 (2004) 481-504]. J Res Pers. 2005;39(1):206-7. doi:10.1016/j.jrp.2004.10.001.

34. Diener E, Suh EM, Lucas RE, Smith HL. Subjective well-being: Three decades of progress. Psychol Bull. 1999;125(2):276-302. doi: 10.1037/0033-2909.125.2.276

35. Behrouz B, Mohammadi F, Aliabadi S, Kajbaf MB, Heidarizadeh N, Behrouz B. [A comparison between personality traits and attribution styles of normal couples and divorce petitioners]. Knowledge Res Appl Psychol. 2014;15(55):52-61. Persian. 